\title{
The impact of a Community Based Rehabilitation Program in Afghanistan: A longitudinal analysis using propensity score matching and difference in difference analysis
}

Jean-Francois Trani ( $\square$ jtrani@wustl.edu )

Washington University in Saint Louis https://orcid.org/0000-0002-9187-0946

Juanita Vasquez-Escallon

UNICEF Cambodia

Parul Bakhshi

Washington University in Saint Louis

\section{Research}

Keywords: Afghanistan, Community Based Rehabilitation, Difference in difference, Disability, Impact evaluation, Low Middle Income Countries, Propensity score matching

Posted Date: August 10th, 2020

DOI: https://doi.org/10.21203/rs.3.rs-54687/v1

License: (c) (1) This work is licensed under a Creative Commons Attribution 4.0 International License.

Read Full License

Version of Record: A version of this preprint was published at Conflict and Health on August 21st, 2021. See the published version at https://doi.org/10.1186/s13031-021-00397-y. 
The impact of a Community Based Rehabilitation Program in Afghanistan: A longitudinal analysis using propensity score matching and difference in difference analysis

Trani* J.F., Vasquez-Escallon\# J., Bakhshi^ P.

* Institute of Public Health, Brown School, Washington University in St Louis.

\# UNICEF, Phnom Penh Cambodia.

${ }^{\wedge}$ Institute of Public Health, Occupational Therapy, Washington University School of Medicine.

Corresponding author: Jean-Francois Trani Associate professor, Brown School, Washington

University in St. Louis, Campus Box 1196, Goldfarb Hall, Room 243, One Brookings Drive, St. Louis, MO 63130 [o] 314.935.9277 [c] 314.412.0077 [e] jtrani@wustl.edu 


\begin{abstract}
Background. The 2006 United Nations Convention on the Rights of Persons with Disabilities states that the achievement of equal rights, empowerment and social inclusion of people with disabilities requires comprehensive rehabilitation services encompassing all components of the World Health Organization Community based rehabilitation (CBR) matrix: health, education, livelihood, social and empowerment. CBR programs specifically aim to deliver such comprehensive interventions. In the present study, we investigate the impact of a CBR program in Afghanistan on all these components.
\end{abstract}

Methods. We enrolled 1861 newly recruited CBR participants with disabilities in the study, from 169 villages between July 2012 and December 2013 as well as 1132 controls with disabilities randomly selected through a two-stage process within 6000 households from 100 villages in the same provinces but outside the catchment area of the CBR program. We interviewed them again after one (midline) and two (end-line) years in the study. Using propensity score matching and difference in difference analysis, we estimated the impact of the CBR on outcomes of interest, namely mobility, activities of daily living, communication, participation in social and community life, emotional well-being and employment.

Results. There were statistically significant differences between participants and controls on all outcomes between baseline and end-line, with impacts ranging from the highest on emotional wellbeing $(1.02,95 \% \mathrm{CI} 0.04-2.00)$ and the lowest on activities of daily living (0.08, CI 0.03$0.13)$.

Conclusion. Our study indicates that a CBR program may provide positive rehabilitation outcomes for persons with disabilities even in a conflict context, and improve overall well-being of all participants with disabilities, whatever their impairment, individual characteristics and the CBR matrix components considered.

Trial registration. ISRCTN, ISRCTN50214054. Registered August 5th 2020 - retrospectively registered, http://www.isrctn.com/ISRCTN50214054

\title{
Keywords
}

Afghanistan; Community Based Rehabilitation; Difference in difference; Disability; Impact evaluation; Low Middle Income Countries, Propensity score matching 


\section{Background}

The 2006 United Nations Convention on the Rights of Persons with Disabilities (UNCRPD) states that the achievement of equal rights, empowerment and social inclusion of people with disabilities requires comprehensive rehabilitation services encompassing educational, social, economic and medical interventions (1). In particular, article 26 of the UNCRPD calls for rehabilitation services and programs to promote more participation of persons with disabilities in their community and in all aspects of broader society. Community Based Rehabilitation (CBR) is a strategy that promotes the "rehabilitation, equalization of opportunities, poverty reduction and social inclusion of all people with disabilities" $(2,3)$.

CBR programs were introduced in the 1970 s as a participatory strategy to use effective, locallydeveloped technologies and interventions to prevent disability and transfer knowledge and skills about disability and rehabilitation to people with disabilities, their families and the community at large involved in the program. CBR was conceived as a combined effort of a diverse group of actors, including families, communities, disabled people's organizations, health and social services provided by governmental and non-governmental actors, and, at the center, people with disabilities themselves.

Advocates of CBR identify several advantages of this approach over other alternatives. First, $\mathrm{CBR}$ is comprehensive; experts have demonstrated that all rehabilitation needs can be addressed through CBR interventions (4-6). Second, authors have argued that CBR programs are more cost-effective than hospital or rehabilitation center-based interventions (7). Third, taking a strong rights-based approach, CBR aims to specifically improve the wellbeing of systematically marginalized people with disabilities (8). Finally, CBR is oriented toward participation and empowerment of people with disabilities $(9,10)$.

Despite the stated strengths, CBR programs continue to face several critiques linked to field realities. The first is that, while nominally based in values of participation and empowerment of people with disabilities, CBR often reproduce the same top-down service delivery approach of other methods (11). Second, it has been argued that CBR are operated and funded by international aid and humanitarian organizations, raising significant questions about the sustainability of programs when donor priorities change (11). Finally, at implementation level, many programs have scarce resources and lack strong support from the community. Absence of 
community involvement leads to poor monitoring despite some recent progress with the elaboration in partnership with CBR stakeholders of a monitoring manual (12-14).

Despite the proposed benefits of CBR, extensive empirical literature that provides evaluation of the impact of CBR programs in diverse contexts is lacking. Most existing studies do not evaluate the overall WHO CBR matrix but overwhelmingly focus on its health component $(15,16)$. Moreover, studies often focus on one condition or type of disability and do not evaluate the impact of CBR programs across disabilities. Notwithstanding the focus of the CBR matrix and the program design on the participation of people with disabilities in communities, few studies examine the contribution of CBR towards fostering empowerment and increasing social inclusion of people with disabilities and their families or change in community attitudes and behavior towards people with disabilities $(8,13,17)$. The general lack of overall evaluation studies is also explained by the absence of standardized outcomes and of a discrete intervention (18).

Finally, sustainability of CBR is overall neglected (19). This research gap is in part the consequence of the prioritization of implementation over evaluation in CBR by development organizations, funders, and policymakers. Most existing research focuses on accessibility, reach of the program, identification of needs and specific rehabilitation and service delivery outcomes (20). Studies that do exist lack consistent methodologies, making comparison across programs challenging and unreliable (15, 21-23). For instance, existing CBR program evaluation studies have non-experimental design with limited size samples (15).

The present impact evaluation study contributes towards filling the gap between theoretical concepts of CBR and the actual implementation of a CBR program in Afghanistan by measuring the impact of CBR activities on the circumstances and well-being of participants with disabilities. Our study is unique in that: (i) it combines a measure of outcomes associated with one of the five components of the CBR matrix - health, education, livelihood, social and empowerment; (ii) it addresses the issue of CBR program sustainability by looking at data from three rounds of interviewing the same CBR cohort of participants and controls with disabilities, showing the lasting effect of the rehabilitation interventions; and (iii) it is one of so far only nine identified studies looking at CBR effectiveness carried out in a low income country; the only one in a conflict context. This paucity of existing evidence makes studies like the present one 
essential to legitimize the promotion of CBR while shedding light on the conditions of its success. This is of utmost importance in LMICs as CBR has been, especially in crisis and emergency contexts, the only set of services available to persons with disabilities, a particularly disadvantaged group in such contexts $(24,25)$.

\section{Methods}

\section{Study aim, design and setting}

The present study investigates the impact of the Swedish Committee for Afghanistan (SCA) CBR using a quasi-experimental design. The CBR is implemented in 13 provinces of northern and eastern Afghanistan (See Map 1) and provides services to an estimated 2,301 persons with disabilities in home-based activities and 1,443 children in home-based education in 2018. The program covered 48 districts with over 775 staff, 863 (413 female) community volunteers and 151 (60 composed of female) CBR committees. The program is managed from four regional project offices based in Ghazni city (Ghazni province), Jalalabad (Nangharar province), Mazare-Sharif (Balkh province) and Taloqan (Takhar province) (See Figure 1).

\section{Figure 1 (approximately here)}

\section{Participant characteristics}

For the present study, we interviewed all new 1680 CBR participants included in the program between July 2012 and December 2013 (see Figure 2). Besides living in one of the 169 villages or urban areas (mahals) of the catchment area of the program, the other inclusion criteria were the ones defined by the CBR program at its start in 2004. At the creation of the program, catchment areas were defined under the following criteria: i) The number of persons screened with a disability using a locally developed, tested and validated questionnaire based on the WHO guidelines for grassroot disability programs to account for contextual factors (26) living in the areas or mahal close to the other SCA activities such as orthopedic workshops and physiotherapy centers/clinics; (ii) mahals had to be the place of residence of the newly recruited CBR workers before the program could expand progressively to nearby villages until it covered the entire district; iii) the willingness of person with disabilities and the family members to participate in the CBR programs; iv) the readiness of a family member to be trained by — and implement — the activities set up by the CBR worker in order for such activities to be ongoing daily, while the CBR worker would check progress made on a weekly or sometimes bi-weekly basis; v) the 
absence in the mahal of a similar intervention by any other organization, and vi) the intervention had to be welcomed by the overall village community and particularly the village council or shurah. On average, one CBR worker was serving 100 participants with disabilities per year. Each expansion was decided in agreement with the CBR program management and the new targeted areas were surveyed for identification of persons with disabilities using the same WHO instrument (26).

Figure 2 (approximately here)

Controls were randomly selected during the same period in villages and urban areas of the same provinces but outside of the catchment area of the CBR program. We used a random number generator to select a first village to include in the sample from the complete list of villages in each region. The subsequent villages were then selected from the list at the sample interval. This process was repeated for all 13 provinces in the study to compile the full list of 100 control villages. 60 households were randomly selected in each village for a total of 6000 households in the sample. In the social center of the village, typically a mosque or an open square, a child was asked to select a number from a small bag, and to spin a spinner. The spinner indicated the direction from which the survey team would begin. Households were selected using the nearest front door method. A household was defined as a unit that shared a kitchen, an income and occupied the same flat, house or compound. All heads of households were interviewed with a locally validated disability-screening tool composed of 34 items for adults (DSQ-34) and 35 for children (DSQ-35) to identify all members of the household with disabilities (27). All study participants were interviewed with a locally developed and validated questionnaire that inquired about demographic characteristics, socioeconomic status, access to rehabilitation, health and social services, individual functioning, social participation, and additional needs. The questionnaire examined the effectiveness of the CBR program in improving the agency of persons with disabilities to determine their daily lives, participate in different aspects of community life, escape stigma and prejudice, and access various CBR services from the five domains of the CBR matrix (health, education, livelihood, social inclusion and empowerment) (2). Disability experts in Afghanistan were asked to review the content of the initial English version of the tool for completeness, content validity, and appropriateness of the questions to the Afghan cultural context. The English version of the tool was then translated into Dari and Pashto by a disability expert from the Ministry of Public Health in Kabul. Several different translators 
worked independently to back-translate the survey into English and compare results to reconcile discrepancies. A first version of the questionnaire developed by the authors was initially tested end of 2011 with a group of 20 CBR participants in Jalalabad, Nangarhar, Afghanistan. Each respondent was interviewed separately by a researcher for consistency check of responses provided. Additionally, the Dari and Pashto versions of the final questionnaire were tested through a series of 30 interviews in Kabul in 2012 with persons with disabilities of different age groups, gender and ethnicity to verify that response process followed, understanding and interpretation of complex or technical terms, such as access to healthcare, available CBR services, participation in family and community activities, and measures of additional needs as well as satisfaction with life were consistent across different socioeconomic background and with the initial concepts conceived in English by the researchers. Respondents were asked the questions as defined by researchers followed by a series of probe questions aiming at capturing their understanding of the questions in light of their own life experience (28). All study participants were interviewed with the same tool three times respectively between July 2012 and December 2013, between July 2013 and December 2014 and finally between July 2014 and December 2015. Attrition rate was $29 \%$ and $8.6 \%$ between round 1 and 3 respectively for participants and controls. Reasons for attrition are as follows: death or migration outside of the catchment area of the study. Refusal to participate in the study was very minimal among participants $(n=14,0.01 \%)$ and higher among controls $(n=173,15.3 \%)$. Yet, there was no significant differences between respondents and non-respondents with respect to the measured characteristics and we therefore assumed that unobserved data were missing at random (29).

\section{Variables}

\section{Outcome variables}

Six main outcomes of interest were included in the questionnaire and assessed through a range of questions: mobility, activities of daily living, communication, participation in social and community life, emotional well-being and employment. Indexes for each domain were created by generating a sum index score from the component items in the questionnaire. Because outcomes were sometimes different between age groups (for example, questions pertaining to ability to bathe oneself were not asked of infants too young to do so on their own), sum index scores were based on total points possible for each age group. Each summary index score was then divided by total points possible according to age and converted to a proportional value 
between 0-1. Difference scores between rounds 3 and 1 were then calculated. Thus, a result of .15 indicates a $15 \%$ increase in points possible within a given domain. Only employment did not result in an index.

\section{Mobility index}

The mobility index was composed of five activities with response choices limited to a Likert scale composed of three choices (I can always, I can with help, I cannot at all) : Can you sit (asked to respondents above 1 year old); Can you stand (above 1 year old); Can you move inside the home (above 1 year old); Can you move outside the home (above 2 year old); Can you walk at least ten steps (above 2 years old).

\section{Activity of daily living index}

The Activity of daily living index was composed of four activities with the same three response choices: Are you able to eat on your own (asked above 4 years old); Are you able to bathe (above 8 years old); Are you able to use the latrine (above 3 years old); Can you dress and undress (above 4 years old).

\section{Communication index}

The communication index focused on the four following functions with the same three response choices: Can you speak (above 2 years old); Can you understand simple instructions (above 2 years old); Can you express needs (above 2 years old); Do you feel confident learning new things (above 4 years old).

\section{Social participation index}

The social participation index comprised a first item below with three response choices (I can without difficulty, I can with some difficulties, no, I cannot at all) and four following items with three different choices (I can always, I can sometimes, no never): Can you make friends outside the family; Are you consulted in family decisions (above 15 years old); Can you join in community activities and ceremonies; Do you feel respected in the community (above 5 years old); Do you feel respected in your family.

\section{Emotional well-being}

The emotional well-being index was composed of five items with three response choices (never, sometimes, always): Do you feel sad (above 5 years old); Do you feel angry (above 5 years old); 
Do you feel worried or distressed (above 5 years old); Do you have nightmares or bad sleep (above 5 years old); Do you have headaches, stomach-aches or nausea (above 5 years old).

\section{Employment}

We asked respondents between 15 and 60 years old if they had a paid job, either in cash or in goods, what was the employment status (7 categories), if it was full time or part time and since when did they work.

\section{Exposure variables}

We did not measure the specific effect of each service delivered by the CBR program. Each participant received services tailored to their needs. The program delivered a set of services including physiotherapy, group training, loans, home based education, center-based education; inclusion in school; home based training, community advocacy and disability awareness. In other words, the present study does not measure the impact of the discrete interventions offered by the program but rather the overall impact of the program as a whole and the combination of interventions on the participants. We cannot assess whether it was the physiotherapy or the home-based education that contributed most to the change in outcomes over time, but rather a combination of interventions as deemed necessary and useful for each participant.

\section{Covariates}

Covariates considered for the calculation of the propensity score included gender, age, cause of disability, disability type, ethnicity, assets owned at baseline, region, age of onset of the disability, household income at baseline, education level and working status at baseline. Moreover, people were also matched according to the baseline levels of the impact variables to ensure that CBR participants and controls started off at similar levels. We also included community-level variables such as distance to a road and its usability for motorized vehicles, availability of electricity, availability and distance to a school and a health center, type of social and political groups in the village, and exposure to different types of disasters or negative events.

\section{Statistical analysis}

We used a quasi-experimental approach that mixed propensity score matching with difference in difference (PSM-DD) to measure the effect of the CBR program. We analyzed the three waves of data collected from treatment and control from surrounding communities, from the onset of the program at baseline until end-line. The PSM framework used baseline data to find the best 
possible control match to the persons that received the CBR program. It is based on potential outcomes: The comparison group includes people with disabilities who would have been eligible to receive the CBR program services but who live outside of the program's catchment areas. The assumption is that the decision on which communities are part of the program is based on observable characteristics. We controlled in the analysis for personal characteristics that might have an effect on the impact of the program (e.g. gender, age, ethnicity, age at disability onset, cause and type of disability, residence, marital status, education level, employment status, assets index, individual and household income). Because all those who are eligible within a catchment area are included in the program we made the reasonable assumption that participant and control groups have similar characteristics overall $(30,31)$.

In mathematical terms, the average treatment effect (ATE) and average treatment effect on the treated (ATT) of the CBR program through its interventions can be estimated using the following formulas:

$$
\begin{gathered}
A T E=\alpha_{A T E}=E\left(Y^{1}-Y^{0}\right) \\
A T T=\alpha_{A T T}=E\left[Y^{1}-Y^{0} \mid D=1\right]=E\left[Y^{1} \mid D=1\right]-E\left[Y^{0} \mid D=1\right],
\end{gathered}
$$

where 1 refers to being in the treatment group and 0 being in the control group. However, the problem is that neither $\mathrm{E}[\mathrm{Y} 0 \| \mathrm{D}=1]$ nor $\mathrm{E}[\mathrm{Y} 1 \| \mathrm{D}=0]$ can be observed, since we did not observe what would have happened to the controls had they received the program, or what would have happened to the treatments had they not received it. We estimated these two counterfactuals by matching each $\mathrm{CRB}$ participant with one or more controls that were similar in key characteristics.

To overcome the possible selection bias of non-random choice of participants and controls and the absence of independence between the effect variable and the treatment variable, we introduced an assumption of conditional independence. We assumed that we observed all the variables $(X)$ that led a person to receive the program. Thus, the estimate for the average treatment effect on the treated (ATT) can be obtained by:

$E\left[Y 1-{\hat{Y_{0}}}_{0} \mid D=1\right]=\frac{1}{n_{1}} \sum_{i D i=1} Y_{1 i}-{ }_{m_{0}}\left(X_{i}\right)$

where $\widehat{m}_{0}\left(X_{i}\right)$ is the non-parametric estimator of $m_{0}(x)=E(Y \mid X=x, D=0)$. Because of the large number of variables $(X)$ on which the CBR program is based, CBR participants and controls are matched on the propensity of being treated given that $(X)$ takes a value of $(x)$ :

$$
p(x)=\operatorname{Pr}(D=1 \mid X=x) .
$$


We assumed the existence of common support which implies that only CBR participants that have a probability of being treated also found in any of the controls were included in the analysis. Similarly, controls with an extremely low probability of being treated were not included either. This method has the advantage of not requiring any assumption on whether the program has homogeneous or heterogeneous effects on the model errors and by being non-parametric it can be combined with other methods in order to yield more precise impact measures (32). We combined PSM with the difference in difference (DD) approach when different points in time were captured to account for all unobservable differences that are stable over time therefore eliminating the risk of selection bias even if some unobservable characteristics that lead to the decision on whether to receive the program could not be captured with the variables $(X)$. PSMDD allowed for measuring the relative difference in change in outcomes over time between CBR participants and controls, and counteract the fact that not all variables that led to the definition of a catchment area could be considered, and thus addresses the bias generated by this limitation. We estimated the PSM using only baseline variables to ensure that people were comparable before any interventions took place. We used STATA 15 for all analyses.

\section{Results}

\section{Bivariate analysis of effect of intervention exposure on outcomes}

Table 1 presents the difference in various outcomes between CBR participants and controls at baseline and end-line. CBR participants show on average higher limitations for all outcomes of interest at baseline. At baseline, a significant higher proportion of CBR participants with disabilities could not carry-out any of the four mobility activities or had some difficulties compared to controls with disabilities. Similarly, CBR participants had significantly more difficulties to accomplish any of the activities of daily living. Results for communication comparisons were consistent with limitations of basic activities of daily living and mobility: overall CBR participants had higher rates of complete or partial limitation than controls except for learning new things, where controls have slightly higher limitations. Study results show that CBR participants faced higher barriers to social participation. Interestingly, perception of lack of respect by family was observed to be very low and less frequent in both groups than perception of lack of respect by the community. Yet, participation in family decisions was very low as approximately $9 \%$ of both CBR participants and controls above age 15 were never consulted. Finally, we found that CBR participants and controls demonstrated very similar and relatively 
low levels of severe mental distress and anxiety; feeling sometimes worried or angry was even significantly higher among controls.

At end-line, all bivariate analysis showed a statistically significant effect of exposure on outcomes. The proportion of CBR participants who had severe activity limitations or functioning difficulties in terms of mobility, activity of daily living, communication and social participation or a low level of emotional wellbeing at baseline saw a significant reduction in the intensity of those limitations and difficulties and a significant improvement in the level of wellbeing at endline. The proportion of CBR participants with severe activity limitations or functioning difficulties or low level of emotional wellbeing at end-line were similar or lower than controls.

Table 1: Effect of the exposure to the CBR program on outcomes of interest (approximately here)

\section{Measuring the effect of the CBR program using Propensity Score Matching with Difference in Difference analysis}

We use PSM-DD to assess the CBR program impact on the various outcomes of interest. Findings reported in Figure 3 and Table 2 show a positive impact of the CBR program on all outcomes of interest. The first graph in Figure 3 presents the change over time in the mobility index for both CBR participants and controls. While the controls saw their mobility worsen slightly by $1.4 \%$, CBR participants' mobility index improved by $13 \%$. The 14.4 percentage point difference between both groups is statistically significant. The second graph shows that both CBR participants and controls improved their capacity to carry out activities of daily living. However, CBR program participants improved by $8.4 \%$ more than controls. Similarly, as shown in the third graph, CBR participants improved their communication abilities by $9.1 \%$ more than controls. The fourth and fifth graphs show a difference in improvement in social participation skills and emotional wellbeing between CBR participants and controls of respectively $17.8 \%$ and $10.2 \%$. Controls even saw their mobility, social participation skills and emotional wellbeing decrease during the three years period of intervention. The last graph in Figure 3 shows that the CBR program promoted access to employment for participants - by $7.5 \%$ on average during the three-year period - while controls underwent a reduction in employment rate during the same period of $4.4 \%$.

Figure 3: (approximately here) 
Table 2: Average treatment effect on the treated (ATT) on all outcomes of interest (approximately here)

\section{Discussion}

Our study shows that the CBR program had a significant positive impact on several outcomes of interest promoted by the WHO, namely individual mobility, activities of daily living, communication skills, emotional wellbeing, social participation and employment. This confirms that CBR programs can improve livelihoods and wellbeing of persons with disabilities in LMICs $(8,20,33,34)$. Yet, existing studies present multiple limitations — small sample size, inadequate sample methodology, mostly observational or qualitative approaches, recall bias in the only existing quasi experiment and lack of accounting for confounding factors in regression analysis $(8,35)$. Our study follows and interviews a large group of CBR participants and a random group of controls multiple times over a period of three years.

The CBR program has a differential impact on the various outcomes indicating that improvement is not uniform but depends on the components of interest. The highest positive impact is observed on emotional wellbeing. After 3 years on average in the program, the estimated marginal effect is a considerable 102\%. The gap between treated and controls is particularly salient because the emotional wellbeing of controls without any dedicated support decreased by $34 \%$ during the period. While we observed such an increase in anxiety and distress among controls during the three years of observation, CBR participants showed a continuous improvement. Anxiety and distress are a major ill in conflict affected contexts such as Afghanistan. Literature traditionally attributed mental distress to the violence itself (36-40) including sexual violence and intimate partner violence (41-44). Increasingly, scholars have also shown that daily stressors play an important role in common and more severe mental disorders, particularly among vulnerable groups. Conflict exacerbates economic deprivation adding an important source of mental distress, particularly for those at risk of being economically and socially excluded (45-47). Literature has shown that persons with disabilities are also particularly at risk of mental distress in conflict settings because of poverty, unemployment but also stigma associated with disability $(48,49)$.

Another important effect of the program was observed on social participation which encompasses important dimensions of social life. The social participation index reveals a person's sense of self-worth and placement within their family and community, and also 
indicates to what extent disability isolates a person from family and community daily life. Effectively changing community attitudes resulting in reduced marginalization and discrimination of persons with disabilities is a major milestone difficult to achieve because of deeply entrenched negative beliefs $(49,50)$. Early CBR literature showed that it was easier to restore individuals' functions than to change contextual factors such as attitudes towards disability (51). Yet, it is a significative achievement, one that embodies the philosophical underpinning of the CBR principles as defined by the World Health Organization: a bottom-up multipronged set of interventions relying on ownership and empowerment of persons with disabilities (2). If this outcome reflects genuine social participation and reduction in prejudice, such achievement also contributes to the principle of "full inclusion and participation in all aspects of life" promoted by the article 26 of the UNCRPD. The fact that controls saw their social involvement in their community and family slightly reduced by $5.1 \%$ confirms that cultural norms and beliefs foster social isolation that only an external intervention promoting awareness and advocacy can progressively and partially remedy $(8,48,52)$.

The significant effect on activities of daily living, communication and mobility demonstrate that a CBR program implemented with limited resources, family support in remote areas prone to violence and disruption associated with conflict, can be effective in providing rehabilitation services through a combination of low cost home-based services such as physiotherapy and access to free orthopedic workshops (53). Literature has shown that caregivers' involvement is key in effectively improving participants with disabilities' functioning outcomes (54). However, by improving the autonomy of persons with disabilities through rehabilitation processes involving family caregivers, the CBR program reduces the burden that otherwise rest exclusively on them in most LMICs in absence of rehabilitation services (55): The limited amount of improvement made over the same period of time among controls with disabilities tends to confirm the restricted access to such services in the mainstream healthcare system of Afghanistan.

The program also had a significant marginal effect of $12 \%$ on employment of adult participants between 15 and 60 years of age compared to control with disabilities of the same age group. This is a major finding considering there are few interventions and even fewer studies showing the impact of CBR programs tackling the livelihood component of the CBR matrix and supporting employment in LMICs (8). Such gap in intervention makes escaping poverty highly elusive for 
persons with disabilities. Overcoming barriers to employment of persons with disabilities is a considerable economic challenge overall. An already 16 years old study estimated at the time that the global gross domestic product loss due to disability to be between $\$ 1.71$ trillion to $\$ 2.23$ trillion annually $(56,57)$. Furthermore, lack of livelihoods intervention undermines resilience and self-esteem of persons with disabilities, particularly men. In Afghanistan, persons with disabilities have been shown to face lower employment and higher multidimensional poverty compared to non-disabled people particularly for young men (58). Yet, men are traditionally expected to be breadwinners and look after the needs of the family $(59,60)$ : For persons with disabilities, the CBR intervention helps secure a job, an essential step towards building a sense of wellbeing resulting from meeting their social obligations and obtaining recognition within the community (61).

Our study presents some limitations. First, there was a risk of self-selection in the CBR program. Elderly people and people with associated disabilities were significantly less likely to participate in the program (53). There was a risk of selection on non-observable variables as well that we tried to minimize by including a large set of control variables in the propensity score calculation and by using difference in difference as an additional methodology to estimate an unbiased impact. Second, there is a risk of information bias as data collection was carried out by CBR workers under the supervision of the investigators and research officers because of security issues. This might have introduced a social desirability bias among CBR workers willing to show a good image of their program. Careful and ongoing supervision in the field and after data collection, consistency checks as well as random re-interviews of participants has made very unlikely that this bias could change our findings. Finally, the selection of catchment areas was not random. However, baseline information shows that CBR participants started worse off than their counterparts, reducing the chance that observed impacts were due to initial differences favoring CBR participants.

\section{Conclusions}

Our results have important implications regarding the capacity of CBR to complement existing government initiatives in addressing the issues related to rehabilitation, autonomy social and economic inclusion of persons with disabilities in a conflict or disaster context and beyond in other LMICs. Better mobility activities of daily living and communication skills are indicators of 
a CBR program that offers effective rehabilitation services. Most importantly, improvement in emotional wellbeing, social participation and even access to jobs show that the CBR program was also effective in advocating for the rights of persons with disabilities and promoting awareness of disability in the community to fight stigma (20). In particular, there is abundant literature exploring the impact of stigma on emotional wellbeing $(62,63)$. One of the central goals of CBR programs in general is to challenge stigma of rural communities towards disability in order to promote people with disabilities' community participation and inclusion (64). Rehabilitation remains incomplete unless it addresses stigma and prejudice towards people with disabilities who frequently cannot envision the future and have no prospect of social inclusion. It is well established that community acceptance is associated with higher emotional wellbeing and self-esteem but we lack evidence of effective stigma-reduction interventions particularly in low income countries (65). Similarly to the Swedish Committee for Afghanistan CBR program, another program in Afghanistan promoted by HealthNet TPO also relied on including people with mental disorders and the community in advocacy (66). The lack of standardization in the CBR program we examined did not allow for identification of specific processes that were most successful in promoting social inclusion. Future research should explore such processes and mechanisms that lead to effective CBR interventions towards persons with disabilities.

\section{List of abbreviations}

CBR: Community Based Rehabilitation

LMIC: Low and Middle Income Country

DSQ34: 34 items Disability Screening Questionnaire

SCA: Swedish Committee for Afghanistan

WHO: World Health Organization

UNCRPD: United Nations Convention on the Rights of Persons with Disabilities

\section{Ethics approval and consent to participate}

The present study was approved by the Human Research Protection Office of Washington University in St Louis (IRB ID \#:201206117) and by the Institutional Review Board of the Ministry of Public Health of Afghanistan. All human studies have been approved by the appropriate ethics committee and have therefore been performed in accordance with the ethical standards laid down in the 1964 Declaration of Helsinki and its later amendments. 


\section{Consent for publication}

Not applicable.

\section{Availability of data and materials}

Data collected for the study, including deidentified individual participant data and a data dictionary defining each field in the set will be made available to others at publication. The data will be made available in the DRYAD repository at https://datadryad.org/stash with investigator support, after approval of a proposal, with a signed data access agreement.

\section{Competing interests}

The authors declare that they have no competing interests.

\section{Funding}

This study was funded by the Swedish International Development Agency, Swedish Committee for Afghanistan and Washington University in St Louis. The funding sources had no role in the conception and the design of the study, the data collection process, the data analysis, in the writing of the manuscript or the decision to submit it for publication. The corresponding author had full access to all the data in the study and had final responsibility for the decision to submit for publication

\section{Authors' contributions}

JFT elaborated the original design of the study, conceived the paper and drafted the manuscript. JFT and PB carried out and supervised the data collection, data entry and data cleaning. JVE and JFT participated in the analysis. JFT and JVE interpreted the data. PB provided overall technical support. All authors read, contributed and approved the final manuscript.

\section{Acknowledgements}

This study would not have been possible without the patience of the 2639 respondents and their families who, year after year, took the time to respond to the questions of the survey team. This work is dedicated primarily to them. All Community Based Rehabilitation Workers and Supervisors involved in the present study. We are deeply thankful to each of them for their support and contributions. 


\section{references}

1. United Nations. Convention on the rights of persons with disabilities. New York: United Nations; 2006.

2. World Health Organization. Community-Based Rehabilitation: CBR Guidelines. Geneva: WHO; 2010.

3. ILO, UNESCO, WHO. Community Based Rehabilitation: A Strategy for Rehabilitation, Equalization of Opportunities, Poverty Reduction and Social Inclusion of People with Disabilities. Joint Position Paper. Geneva: United Nations; 2004.

4. DFID. Disability, poverty and development. 2000.

5. Eldar R. Integrated institution - community rehabilitation in developed countries: a proposal. Disability and Rehabilitation. 2000;22(6):266-74.

6. Helander E, United Nations Development Programme. Interregional Programme for Disabled P. Prejudice and dignity: an introduction to community-based rehabilitation. New York: United Nations Development Programme; 1993.

7. Mitchell R. The research base of community-based rehabilitation. Disability \& rehabilitation. 1999;21(10\&11):459-68.

8. Mauro V, Biggeri M, Grilli L. Does Community-Based Rehabilitation Enhance the Multidimensional Well-Being of Deprived Persons With Disabilities? A Multilevel Impact Evaluation. World Development. 2015;76:190-202.

9. Cornielje H. The Role and Position of Disabled People's Organisations in Community Based Rehabilitation: Balancing Between Dividing Lines. Asia Pacific Disability Rehabilitation Journal. 2009;20(1):3-14.

10. Sharma M. Community participation in community-based rehabilitation programmes. Asia Pacific Disability Rehabilitation Journal. 2007;18(2):146-57.

11. Turmusani M, Vreede A, Wirz SL. Some ethical issues in community-based rehabilitation initiatives in developing countries. Disability and Rehabilitation. 2002;24(10):558-

64.

12. Madden RH, Lukersmith S, Millington MJ, Scarf C, Fortune N, Hartley S, et al. Participatory monitoring of community-based rehabilitation and other disability-inclusive development programmes: The development of a manual and menu. Disability, CBR and Inclusive Development. 2016;26(4):26-52.

13. Chappell P, Johannsmeier C. The impact of community based rehabilitation as implemented by community rehabilitation facilitators on people with disabilities, their families and communities within South Africa. Disability \& Rehabilitation. 2009;31(1):7-13.

14. Kuyini AB, Alhassan A-RK, Mahama FK. The ghana community-based rehabilitation program for people with disabilities: what happened at the end of donor support? Journal of Social Work in Disability \& Rehabilitation. 2011;10(4):247-67.

15. Iemmi V, Blanchet K, Gibson LJ, Kumar KS, Rath S, Hartley S, et al. Community-based rehabilitation for people with physical and mental disabilities in low- and middle-income countries: a systematic review and meta-analysis. Journal of Development Effectiveness. 2016;8(3):368-87.

16. Saran A, White H, Kuper H. Evidence and gap map of studies assessing the effectiveness of interventions for people with disabilities in low-and middle-income countries. Campbell Systematic Reviews. 2020;16(1). 
17. Mitchell RA, Zhou D, Lu Y, Watts G. Community-based rehabilitation: does it change community attitudes towards people with disability? Disability and Rehabilitation.

1993;15(4):179-83.

18. Hartley S, Finkenflugel H, Kuipers P, Thomas M. Community-based rehabilitation: opportunity and challenge. The Lancet. 2009;374(9704):1803-4.

19. Mijnarends D, Pham D, Swaans K, Van Brakel W, Wright P. Sustainability criteria for CBR programmes-two case studies of provincial programmes in Vietnam. Disability, CBR \& Inclusive Development. 2011;22(2):3-21.

20. Biggeri M, Deepak S, Mauro V, Trani JF, Kumar J, Ramasamy P. Do community-based rehabilitation programmes promote the participation of persons with disabilities? A case control study from Mandya District, in India. Disability and Rehabilitation. 2014;36(18):1508-17.

21. Alavi Y, Kuper H. Evaluating the impact of rehabilitation in the lives of people with disabilities and their families in low and middle income countries. A review of tools. 2010.

22. Cornielje H, Velema JP, Finkenflügel H. Community based rehabilitation programmes: monitoring and evaluation in order to measure results. Leprosy Review. 2008;79(1):36-49.

23. Velema JP, Ebenso B, Fuzikawa PL. Evidence for the effectiveness of rehabilitation-inthe-community programmes. Leprosy Review. 2008;79(1):65-82.

24. dos Santos-Zingale M, McColl MA. Disability and participation in post-conflict situations: The case of Sierra Leone. Disability \& Society. 2006;21(3):243-57.

25. Kett M, van Ommeren M. Disability, conflict, and emergencies. The Lancet. 2009;374(9704):1801-3.

26. World Health Organisation. Training in the community for people with disabilities: Guide for Local Supervisors. Geneva: World Health Organization; 1989.

27. Trani JF, Babulal GM, Bakhshi P. Development and Validation of the 34-Item Disability Screening Questionnaire (DSQ-34) for Use in Low and Middle Income Countries Epidemiological and Development Surveys. PLOS ONE. 2015;10(12).

28. DeMaio T, Rothgeb J. Cognitive interviewing techniques: in the lab and in the field. In: Schwarz N, Sudman S, editors. Answering Questions Methodology for Determining Cognitive and Communicative Processes in Survey Research. San Francsico:: Jossey-Bass, Ine; 1996. p. 177-96.

29. Little RJ, Rubin DB. Statistical analysis with missing data: John Wiley \& Sons; 2014.

30. Rosenbaum PR, Rubin DB. The central role of the propensity score in observational studies for causal effects. Biometrika. 1983;70(1):41-55.

31. Rubin DB. Estimating causal effects of treatments in randomized and nonrandomized studies. Journal of Educational Psychology. 1974;66(5):688-701.

32. Blundell R, Costa Dias M. Alternative Approaches to Evaluation in Empirical Microeconomics. Portuguese Economic Journal. 2002;1:91-115.

33. Mauro V, Biggeri M, Deepak S, Trani JF. The effectiveness of community-based rehabilitation programmes: an impact evaluation of a quasi-randomised trial $\mathrm{J}$ Epidemiol Community Health. 2014;68(11):1102-8.

34. Chappell P, Johannsmeier C. The impact of community based rehabilitation as implemented by community rehabilitation facilitators on people with disabilities, their families and communities within South Africa. Disability and Rehabilitation. 2009;31(1):7-13.

35. Patel S, Alavi Y, Lindfield R, Kuper H. The impact of rehabilitative services in the lives of adults and children with disabilities, in low-income and middle-income countries: An assessment of the quality of the evidence. Disability and Rehabilitation. 2013;35(9):703-12. 
36. Miller K, Rasmussen A. War exposure, daily stressors, and mental health in conflict and post-conflict settings: Bridging the divide between trauma-focused and psychosocial frameworks. Social Science \& Medicine. 2010;70:7-16.

37. Reed RV, Fazel M, Jones L, Panter-Brick C, Stein A. Mental health of displaced and refugee children resettled in low-income and middle-income countries: risk and protective factors. Lancet. 2012;379(9812):250-65.

38. Steel Z, Chey T, Silove D, Marnane C, Bryant RA, Van Ommeren M. Association of torture and other potentially traumatic events with mental health outcomes among populations exposed to mass conflict and displacement: a systematic review and meta-analysis. Jama. 2009;302(5):537-49.

39. Llosa AE, Casas G, Thomas H, Mairal A, Grais RF, Moro M-R. Short and longer-term psychological consequences of Operation Cast Lead: documentation from a mental health program in the Gaza Strip. Conflict and Health. 2012;6(1):8.

40. Londoño A, Romero P, Casas G. The association between armed conflict, violence and mental health: a cross sectional study comparing two populations in Cundinamarca department, Colombia. Conflict and Health. 2012;6(1):12.

41. Tol WA, Stavrou V, Greene MC, Mergenthaler C, Van Ommeren M, García Moreno C. Sexual and gender-based violence in areas of armed conflict: A systematic review of mental health and psychosocial support interventions. Conflict and Health. 2013;7(1).

42. Kiss L, Quinlan-Davidson M, Pasquero L, Tejero PO, Hogg C, Theis J, et al. Male and LGBT survivors of sexual violence in conflict situations: A realist review of health interventions in low-and middle-income countries. Conflict and Health. 2020;14(1).

43. Horn R, Puffer ES, Roesch E, Lehmann H. Women's perceptions of effects of war on intimate partner violence and gender roles in two post-conflict West African Countries: consequences and unexpected opportunities. Conflict and Health. 2014;8(1):12.

44. Murphy M, Ellsberg M, Contreras-Urbina M. Nowhere to go: disclosure and helpseeking behaviors for survivors of violence against women and girls in South Sudan. Conflict and Health. 2020;14(1):6.

45. Miller K, Omidian P, Rasmussen A, Yaqubi A, Daudzi H. Daily stressors, war experiences, and mental health in Afghanistan. Transcultural Psychiatry. 2008;45(4):611-39.

46. Betancourt T, Agnew-Blais J, Gilman S, Ellis B. Past horrors, present struggles: The role of stigma in the association between war experiences and psychosocial adjustment among former child soldiers in Sierra Leone. Social Science \& Medicine. 2010;70:17-26.

47. Panter-Brick C, Eggerman M, Gonzalez V, Safdar S. Violence, suffering, and mental health in Afghanistan: a school-based survey. The Lancet. 2009;374:807-16.

48. Trani JF, Bakhshi P. Vulnerability and mental health in afghanistan: Looking beyond war exposure. Transcultural Psychiatry. 2013;50(1):108-39.

49. Trani JF, Ballard E, Pena J. Stigma of persons with disabilities in Afghanistan:

Examining the pathways from stereotyping to mental distress. Social Science \& Medicine. 2016;153:258-65.

50. Cerveau T. Deconstructing myths; facing reality. Understanding social representations of disability in Afghanistan. In: Trani JF, editor. Development efforts in Afghanistan: Is there a will and a way? The case of disability and vulnerability. Ethique economique. Paris: L'Harmattan; 2011. p. 103-22.

51. Thomas M, Thomas MJ. A discussion on the shifts and changes in community based rehabilitation in the last decade. Neurorehabilitation and neural repair. 1999;13(3):185-9. 
52. Trani JF, Bakhshi P. Profiling and understanding people with disabilities in Afghanistan. In: Trani JF, editor. Development effort in Afghanistan: Is there a will and a way? The case of disability and vulnerability. Ethique economique. Paris: L'Harmattan; 2011. p. 73-102.

53. Trani JF, Vasquez-Escalon J, Bakhshi P. Home Based Intervention Disability Program Impact Evaluation Study. Final Report. St Louis: Brown School Washington University in St Louis; 2017.

54. Asher L, Hanlon C, Birhane R, Habtamu A, Eaton J, Weiss HA, et al. Community-based rehabilitation intervention for people with schizophrenia in Ethiopia (RISE): A 12 month mixed methods pilot study. BMC Psychiatry. 2018;18(1).

55. Evans PJ, Zinkin P, Harpham T, Chaudury G. Evaluation of community-based rehabilitation for disabled persons in developing countries. Social Science and Medicine. 2001;53(3):333-48.

56. Metts R, Mondiale B. Disability and Development, background paper for the World Bank. World Bank Washington DC Retrieved from http://siteresources worldbank org/DISABILITY/Resources/280658-1172606907476/mettsBGpaper pdf. 2004.

57. Saran A, White H, Kuper H. Evidence and gap map of studies assessing the effectiveness of interventions for people with disabilities in low-and middle-income countries. Campbell Systematic Reviews. 2020;16(1):e1070.

58. Trani J-F, Kuhlberg J, Cannings T, Chakkal D. Multidimensional poverty in Afghanistan: who are the poorest of the poor? Oxford Development Studies. 2016;44(2):220-45.

59. Dupree N. The historical and cultural context of disability in Afghanistan. In: Trani JF, editor. Development effort in Afghanistan: Is there a will and a way? The case of disability and vulnerability. Ethique economique. Paris: L'Harmattan; 2011. p. 284.

60. Centlivres P, Centlivres-Demont M. Et si on parlait de l'Afghanistan? Paris: Maison des Sciences de l'Homme; 1988.

61. Trani JF, Bakhshi P, Rolland C. Capabilities, Perception of Well-being and Development Effort: Some Evidence from Afghanistan. Oxford Development Studies. 2011;39(4):403-26. 62. Hatzenbuehler ML, Phelan JC, Link BG. Stigma as a fundamental cause of population health inequalities. American Journal of Public Health. 2013;103(5):813-21.

63. Shtayermman O. An exploratory study of the stigma associated with a diagnosis of asperger's syndrome: The mental health impact on the adolescents and young adults diagnosed with a disability with a social nature. Journal of Human Behavior in the Social Environment. 2009;19(3):298-313.

64. World Health Organization, World Bank. World report on disability. Geneva: World Health Organization; 2011.

65. Li L, Guan J, Liang LJ, Lin C, Wu Z. Popular opinion leader intervention for HIV stigma reduction in health care settings. AIDS Education and Prevention. 2013;25(4):327-35.

66. Ventevogel P, van de Put W, Faiz H, van Mierlo B, Siddiqi M, Komproe IH. Improving access to mental health care and psychosocial support within a fragile context: A case study from Afghanistan. Plos Medicine. 2012;9(5). 


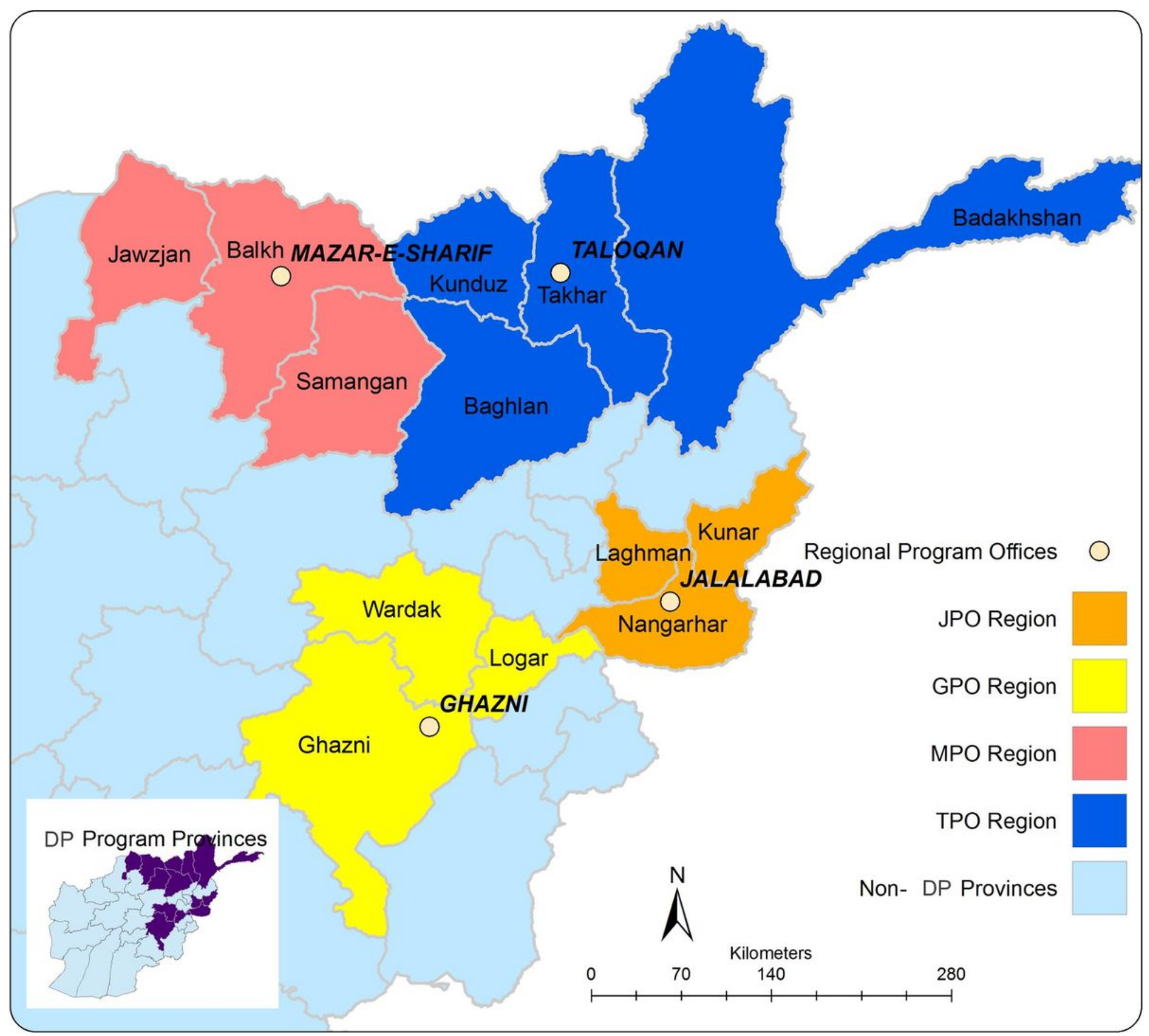

\section{Figure 1}

Map of the CBR program interventions areas Legend: JPO: Jalalabad Provincial Office, GPO: Ghazni Provincial Office, MPO: Mazar-I-Sharif Provincial Office, TPO: Taloqan Provincial Office. Note: The designations employed and the presentation of the material on this map do not imply the expression of any opinion whatsoever on the part of Research Square concerning the legal status of any country, territory, city or area or of its authorities, or concerning the delimitation of its frontiers or boundaries. This map has been provided by the authors. 


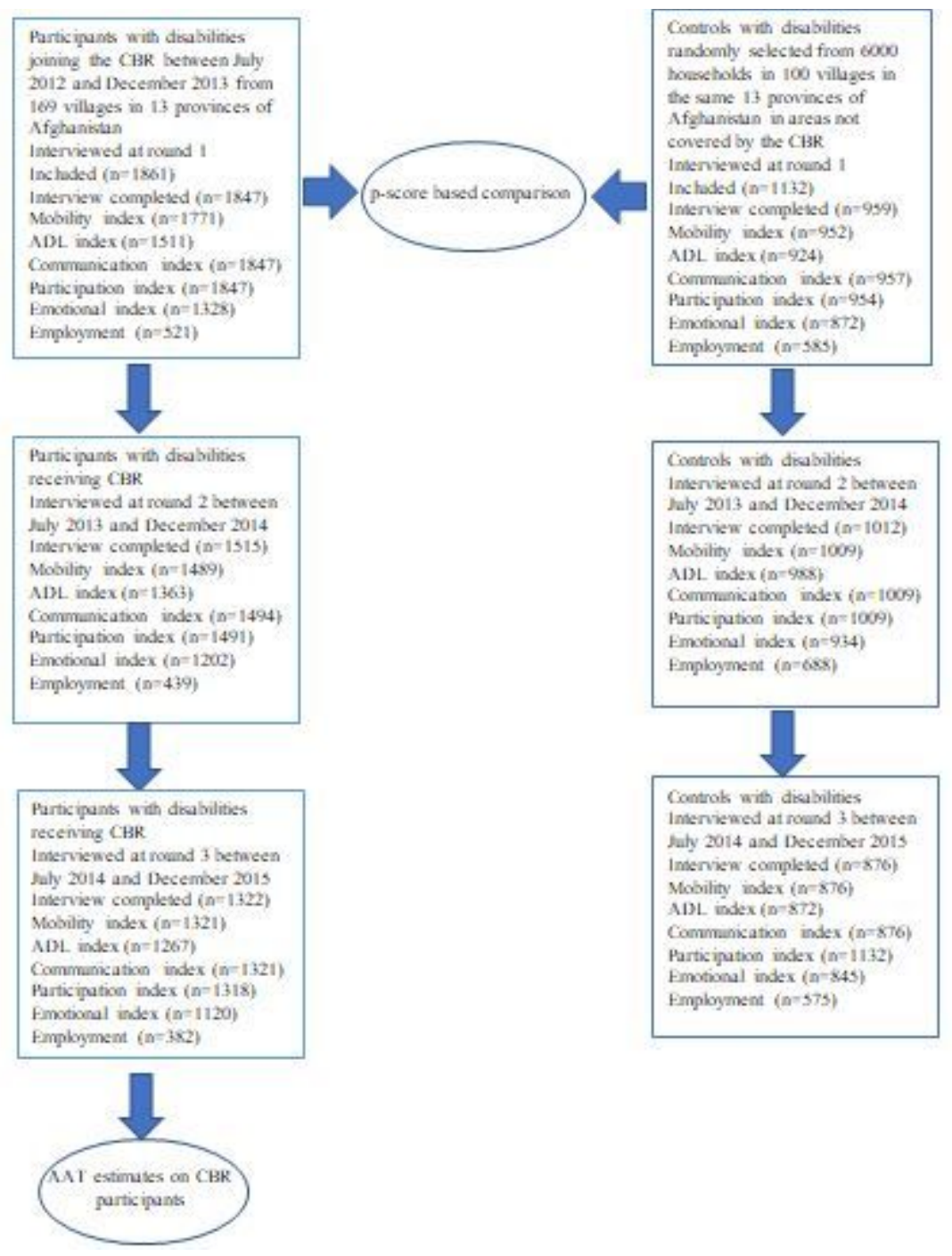

Figure 2

Study participants selection, intervention and follow up process 

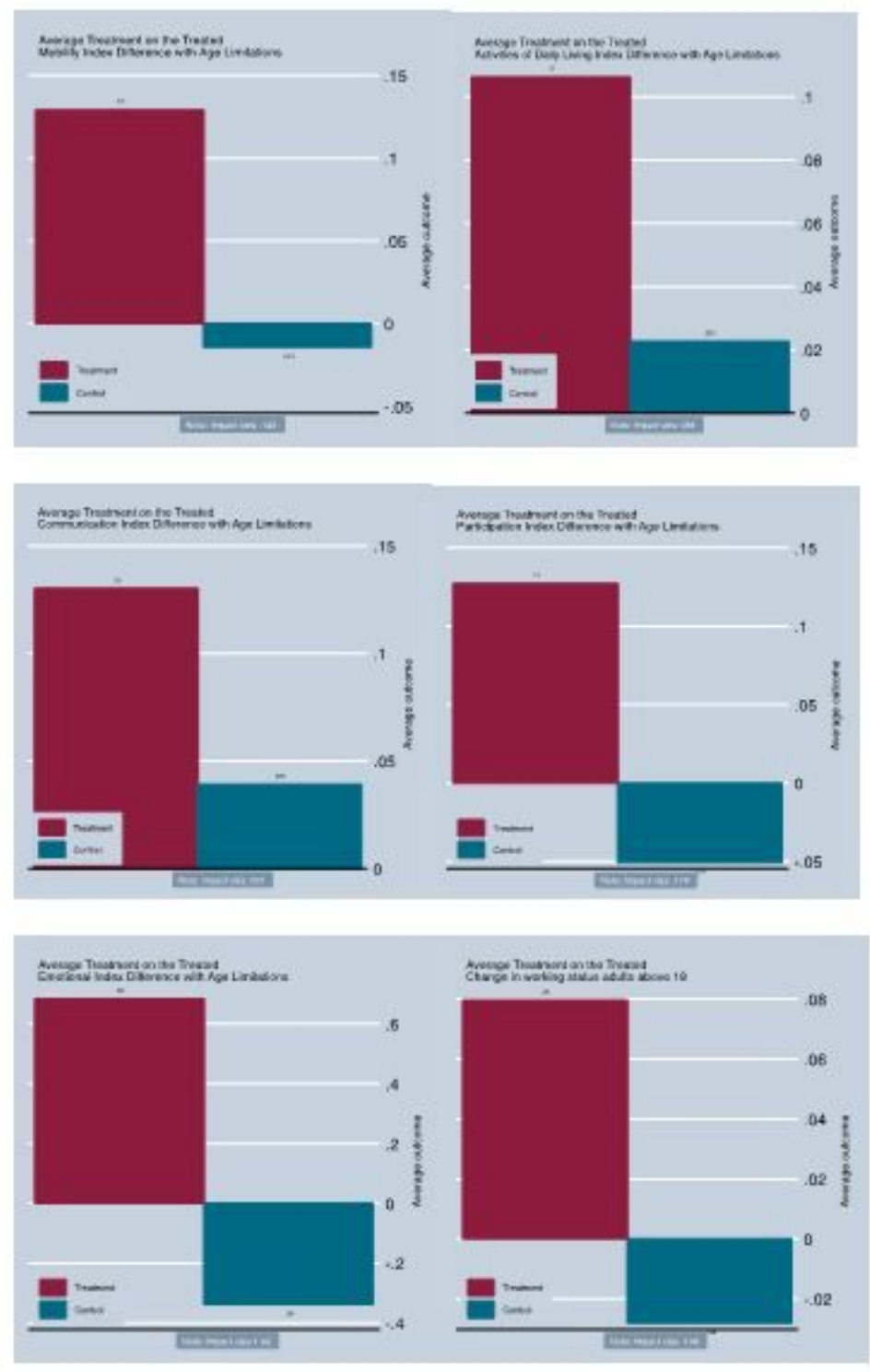

Figure 3

Impact of the CBR program on outcomes of interest using PSM-DD 